\title{
STOCHASTIC MODELING OF COMPRESSIVE STRENGTH OF PHOSPHORUS SLAG CONTENT CEMENT
}

\author{
${ }^{\#}$ ALI ALLAHVERDI*,**, MOSTAFA MAHINROOSTA* \\ *Cement Research Center, School of Chemical Engineering, Iran University of Science and Technology, \\ Narmak 1684613114, Tehran, Iran \\ **Research laboratory of Inorganic Chemical Process Technologies, School of Chemical Engineering, \\ Iran University of Science and Technology, Narmak 1684613114, Tehran, Iran \\ \#E-mail: ali.allahverdi@iust.ac.ir
}

Submitted January 7, 2016; accepted April 14, 2016

\begin{abstract}
Keywords: Blaine fineness, Curing time, Prediction, Composition
One of the common methods for quick determination of compressive strength as one of the most important properties for assessment of cement quality is to apply various modeling approaches. This study is aimed at finding a model for estimating the compressive strength of phosphorus slag content cements. For this purpose, the compressive strengths of chemically activated high phosphorus slag content cement prepared from phosphorus slag (80 wt. \%), Portland cement (14 wt. \%) and a compound chemical activator containing sodium sulfate and anhydrite (6 wt. \%) were measured at various Blaine finenesses and curing times. Based on the obtained results, a primary stochastic model in terms of curing time and Blaine fineness has been developed. Then, another different dataset was used to incorporate composition variable including weight fractions of phosphorus slag, cement, and activator in the model. This model can be effectively used to predict the compressive strength of phosphorus slag content cements at various Blaine finenesses, curing times, and compositions.
\end{abstract}

\section{INTRODUCTION}

Environmental pollution is one of the serious global problems. The production of Portland cement in the cement industry not only consumes raw materials and large amounts of energy, but also as one of the primary industrial producers of carbon dioxide $\left(\mathrm{CO}_{2}\right)$, contributes to the greenhouse effect and causes acid rain. Actually, this industry generates greenhouse gases (GHGs) both directly through the emission of $\mathrm{CO}_{2}$ when clinker is produced and also through the consumption of energy [1-4]. On the other hand, the severity of environmental regulations is enhanced progressively and has forced the industries to put in a great effort to reduce their pollutants [4].

One of the growing approaches for a reduction of air contamination and also obtaining technological, economic, and environmental benefits is the increasing usage of industrial by-products and wastes such as fly ash, silica fume, and different types of slags [1-6]. Among these industrial wastes, only slags such as blast furnace slag (BFS) [5, 7, 8], steel slag [9-11], and phosphorus slag (PHS) [1, 12-15] have latent cementing property and have attracted attention of many researches $[5,11$, 16]. In fact, the production of slag cements and Portlandslag cements results in resource conservation, reducing energy consumption and minimizing emission of GHGs, especially $\mathrm{CO}_{2}$ [2].

\section{Phosphorus slag}

PHS is an industrial by-product that is similar to BFS. PHS is mainly composed of calcium oxide $(\mathrm{CaO})$ and silicon dioxide $\left(\mathrm{SiO}_{2}\right)$. The $\mathrm{CaO}: \mathrm{SiO}_{2}$ ratio of PHS usually varies from 0.8 to 1.2 . From chemical composition, it can be understood that PHS is a latent cementing material but less reactive than BFS $[14,15]$. The residual phosphorus of PHS has a retarding effect on setting time of Portland cement, and insufficient content of $\mathrm{Al}_{2} \mathrm{O}_{3}$ also affects early properties. Slags containing sufficient $\mathrm{Al}_{2} \mathrm{O}_{3}$ exhibit a higher reactivity during early ages. Also, higher $\mathrm{Al}_{2} \mathrm{O}_{3}$ content in the slag increases the aluminum incorporation in calcium silicate hydrate (C-S-H) as one of main hydration products contributing in compressive strength development [17]. As already known, the cement hydration reactions progress in an alkaline environment. Residual phosphorus in the form of $\mathrm{P}_{2} \mathrm{O}_{5}$ leads to the formation of phosphoric acid and consequently $\mathrm{pH}$ of the environment decreases. This is a negative factor that acts as a retarder for progress of hydration reactions and prolongs the setting time $[14,15$, 18]. Therefore, it is necessary to apply valid methods like mechanical activation, chemical activation, and thermal curing to tailor early properties $[1,12]$. In the present study, in order to improve early strength properties of high PHS containing cement (PHSC), mechanical and chemical activation techniques were simultaneously 
used. The prepared cement by these techniques is called chemically activated high phosphorus slag content cement (CAPHSC). This new environment-friend cement exhibits 28-day compressive strength of almost $93 \mathrm{MPa}$ at high Blaine fineness of $450 \mathrm{~m}^{2} \cdot \mathrm{kg}^{-1}$ [19]. Another study has confirmed a significantly better resistance for this cement against frost-salt attack [20]. The mechanical activation was performed in a laboratory ball mill and the chemical activation was done by adding a compound chemical activator. This activator was selected according to some researches. It is based on Portland cement and composed of mixture of various solid chemical activators including anhydrite and sodium sulfate [1, 21-23]. The details of the mechanical and chemical activations are not within the scope of this study. In this paper, the main focus is on finding a stochastic model for prediction of compressive strength of PHSCs. However, it must be noted that this model is not a generalized model for all types of slag containing cements and it can only be used to predict the compressive strength of PHSCs and its applicability for the other types of slag containing cements needs further investigations.

\section{Compressive strength prediction}

In general, compressive strength, durability and sustainability are considered to be of the most important engineering properties of hardened concretes and mortars $[24,25]$. Modeling of compressive strength is performed within the scope of this study, but comprehensive research works are necessary to include durability and sustainability. Exploring the concrete and mortar behavior is an interesting area for researchers resulting in many attentions to prediction of compressive strength via modeling [25]. Common modeling approaches for the prediction of strength properties were generally used including analytical modeling [18, 26, 27] artificial neural network [28, 29-37], and statistical methods [38-41]. A common classification for the different formulas available for the prediction of compressive strength includes [24]: 1) cement composition-based formulas, 2) constituent-based formulas, 3) maturity concept-based formulas, and 4) strength formulas based on age and the other characteristics.

The models based on experimental data often take the factors such as age of curing, curing temperature, water-to-cement ratio, Blaine fineness, composition, and some other ones into account, but there is not a comprehensive model that considers the effect of all these factors, yet [42, 43]. In our previous study [44], a model was developed based on a traditional approach, namely linear regression and dimensionless variables and was in terms of two variables of curing time and water-tocement ratio. The effect of cement composition has not been taken into account in it. In the present study, among five variables of curing temperature, composition, curing time, Blaine fineness, and water-to-cement ratio, only the first one is considered fixed at $25^{\circ} \mathrm{C}$. The composition includes three variables related to weight fractions of PHS, cement, and the activator. Between two variables of Blaine fineness and water-to-cement ratio, only one of them (here Blaine fineness) is incorporated into the model. Eventually, the final model will be in terms of five variables of curing time, Blaine fineness, weight fractions of PHS, Portland cement, and the activator.

Many different resources are available in the literature for compressive strength details on stochastic modeling [39, 45, 46]. The word "stochastic" means "random" or "chance". The antonym is "sure", "deterministic", or "certain". A deterministic model predicts a single outcome from a given set of circumstances. A stochastic model predicts a set of possible outcome weighted by probablities [45]. A "random number" or "stochastic variable" is an object X defined by a set of possible values, called "ranges", "set of states", "sample space" or "phase space" and a probablity distribution is performed over this set [41]. All properties of concrete and mortar in meso-structure level show some randomness in nature. This is a reason that leads researchers to consider randomness or stochastic concept $[40,41]$. This fact, at a glance, is considered in this paper in modeling approach. Here, the problem is considered as predicting the compressive strength of PHSC mortar which develops in mortar stochastically. The purpose of this study is to develop a stochastic model in terms of curing time, Blaine fineness, weight fractions of PHS, Portland cement, and the activator for the prediction of compressive strength of PHSCs.

\section{EXPERIMENTAL}

\section{Materials}

PHS used in this study was prepared from a phosphoric acid plant production located in southeast of Tehran, Iran. The X-ray diffractogram of the PHS is depicted in Figure 1. The peaks of periclase $(\mathrm{MgO})$ was observed as the only crystalline phase. According to ASTM standard C188, the specific gravity of the PHS was determined as $2940 \mathrm{~kg} \cdot \mathrm{m}^{-3}$. Table 1 presents

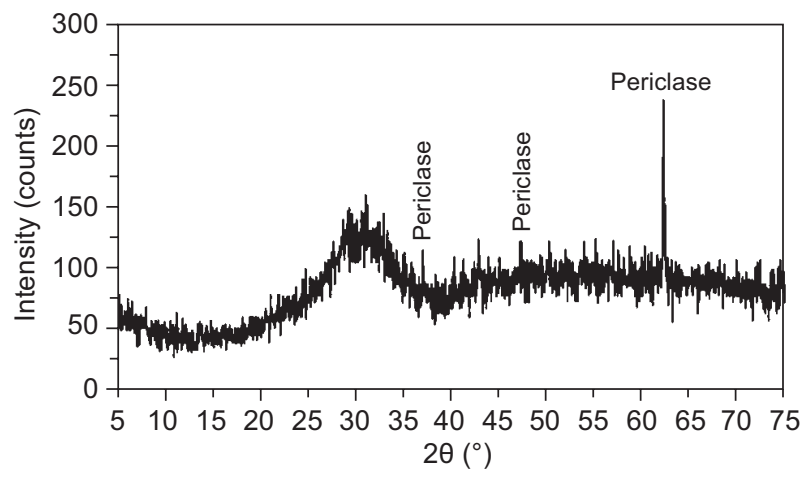

Figure 1. X-ray diffractogram of granulated phosphorus slag. 
its chemical composition determined in accordance with ASTM standard C311. Chemical composition data given in Table 1 confirm the relative quality of the PHS due to its relatively high $\mathrm{SiO}_{2}$ and $\mathrm{CaO}$ contents based on ASTM standard C618.

ASTM Type II Portland cement (PC) was used

Table 1. Chemical composition of granulated phosphorus slag and Portland cement (in wt. \%).

\begin{tabular}{lcc}
\hline & PHS & PC \\
\hline $\mathrm{CaO}$ & 45.14 & 63.26 \\
$\mathrm{SiO}_{2}$ & 38.42 & 22.50 \\
$\mathrm{Al}_{2} \mathrm{O}_{3}$ & 7.65 & 4.15 \\
$\mathrm{Fe}_{2} \mathrm{O}_{3}$ & 0.90 & 3.44 \\
$\mathrm{MgO}$ & 2.60 & 3.25 \\
$\mathrm{SO}_{3}$ & - & 1.80 \\
$\mathrm{~K}_{2} \mathrm{O}$ & 0.56 & 0.65 \\
$\mathrm{Na}_{2} \mathrm{O}$ & 0.43 & 0.20 \\
$\mathrm{LOI}$ & 1.87 & 0.61 \\
Free lime & - & 0.72 \\
$\mathrm{P}_{2} \mathrm{O}_{5}$ & 1.50 & - \\
\hline
\end{tabular}

Bogue's potential phase composition (wt. \%)

\begin{tabular}{lrr}
\hline $\mathrm{C}_{3} \mathrm{~S}$ & - & 45.62 \\
$\mathrm{C}_{2} \mathrm{~S}$ & - & 30.16 \\
$\mathrm{C}_{3} \mathrm{~A}$ & - & 5.18 \\
$\mathrm{C}_{4} \mathrm{AF}$ & - & 10.47 \\
\hline $\left.\mathrm{C}: \mathrm{CaO} ; \mathrm{S}: \mathrm{SiO}_{2} ; \mathrm{A}_{2} \mathrm{Al}_{2} \mathrm{O}_{3} ; \mathrm{F}: \mathrm{Fe}_{2} \mathrm{O}_{3}\right)$ &
\end{tabular}

in this study. The Blaine specific surface area and the specific gravity of PC were $302 \mathrm{~m}^{2} \cdot \mathrm{kg}^{-1}$ and $3120 \mathrm{~kg} \cdot \mathrm{m}^{-3}$, respectively. Table 1 presents the chemical composition and Bogue's potential phase composition of this cement.

Compound chemical activator used in this study was prepared from a blend of 2 wt. \% sodium sulfate (Merck, Germany) and 4 wt. \% anhydrite. The chemical composition of anhydrite (in wt. \%) was as follows: $\mathrm{CaO}-36.00, \mathrm{SO}_{3}-54.38$, and $\mathrm{SiO}_{2}-5.88$.

\section{Methods}

As shown in Figure 2, after mixing of PHS (80 wt. \%), PC (14 wt. \%) and compound chemical activator (6 wt. \%), inter-grinding of them was carried out in a laboratory ball mill with the length and diameter of 0.30 and $0.26 \mathrm{~m}$, respectively. Inter-grinding was continued to the target Blaine fineness levels of 205, 250, 303, 351, 400, and $450 \mathrm{~m}^{2} \mathrm{~kg}^{-1}$.

The values of the Blaine specific surface area were determined in accordance with ASTM standard C204 by using Blaine air-permeability apparatus.

The water-to-cement ratios of mortars in normal consistency were obtained based on ASTM standard C230 by means of a flow table. For this test, PC mortar of normal consistency was used as reference. Water-tocement ratio for PC mortar was 0.485 .

Mortar specimens of the size $5 \times 5 \times 5 \mathrm{~cm}^{3}$ were

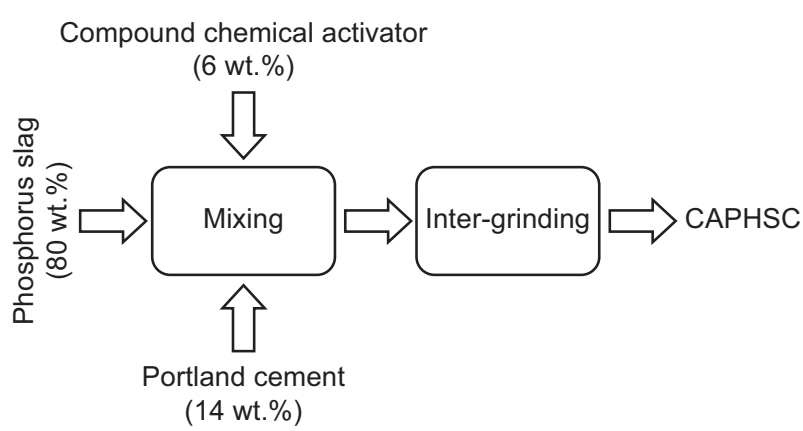

Figure 2. Schematic of preparation steps of chemically activated high phosphorous slag content cement.

prepared for each Blaine fineness in accordance with ASTM standard C109. After casting, the molds were stored in a moist cabinet with an atmosphere of more than $95 \%$ relative humidity at $25^{\circ} \mathrm{C}$ for the first $24 \mathrm{~h}$ and then after demolding, the specimens were cured in limesaturated water at $23 \pm 2{ }^{\circ} \mathrm{C}$ until the time of testing.

Compressive strength of CAPHSC mortar specimens at different ages of $7,14,28,90$, and 180 days was measured using a uniaxial hydraulic press (SCL STD 30) with $\pm 1 \%$ accuracy. Three cubic mortar specimens were used for each curing time and each Blaine fineness and the average of the three values was reported as the result.

\section{THEORETICAL \\ Modeling}

The stochastic modeling is done using two various datasets. One dataset is obtained from our original experimental work and the other one has been adopted from a different source in the literature. The modeling process is performed in two phases. In phase 1, a primary model is derived in terms of Blaine fineness and curing time based on our original experimental results. We call this primary model as age-fineness model (AF model). In phase 2 of the modeling, a coefficient will be incorporated in the AF model. This coefficient as a function of weight fractions of PHS, PC, and the activator will be determined using the dataset taken from a different reference.

\section{Phase 1: primary model}

The compressive strength data obtained from our experimental work are given in Table 2. First step of the modeling in this phase is to have a certain construction route for obtaining a proper model. Then, by using this route, the effect of factors such as Blaine fineness and curing time on the compressive strength of CAPHSC mortar are taken into account. The suggested route as shown in Figure 3 could be used to develop a prediction 
equation for compressive strength property of CAPHSC mortar. This figure is a flowchart showing the executional steps for obtaining the stochastic primary model.

Table 2. Experimental compressive strength data for CAPHSC mortar.

\begin{tabular}{cccccc}
\hline $\begin{array}{c}\text { Blaine fineness } \\
\left(\mathrm{m}^{2} \mathrm{~kg}^{-1}\right)\end{array}$ & \multicolumn{5}{c}{ Compressive strength (MPa) } \\
\cline { 2 - 6 } & 7 days & 14 days & 28 days & 90 days & 180 days \\
\hline 205 & 14.32 & 27.73 & 39.32 & 58.93 & 72.84 \\
250 & 21.92 & 34.41 & 46.90 & 67.33 & 81.53 \\
303 & 33.32 & 45.81 & 58.30 & 79.34 & 91.83 \\
351 & 44.77 & 57.26 & 69.75 & 90.79 & 101.53 \\
400 & 56.28 & 68.77 & 81.40 & 102.30 & 114.80 \\
450 & 67.38 & 79.87 & 92.93 & 113.40 & 125.89 \\
\hline
\end{tabular}

According to steps presented in Figure 3, at the beginning, the the compressive strength is selected as the stochastic variable. Then, a proper initial model is considered in terms of one of the independent variables (here curing time). In the next step, the residuals of compressive strength are calculated and a suitable secondary model is chosen to correlate these residuals with the other independent variable (here Blaine fineness). Final AF model is obtained from summation of initial and secondary models. Next step is attributed to the calculation of errors and consequently accuracy of the AF model. If the errors are not reasonable, it is necessary to return to initial model selection step or secondary model selection step and repeat the steps to the end.

The sign convention for the data used in this section has been denoted as follows:

$\psi$ is compressive strength (MPa),

$\tau$ is curing time (day),

$\gamma$ is Blaine fineness $\left(\mathrm{m}^{2} \cdot \mathrm{kg}^{-1}\right)$.

Based on the above-mentioned steps, at first, a proper non-linear model for the data is selected by following Equation 1:

$$
\psi=\alpha \cdot \ln (1 / \tau)+\eta
$$

where $\alpha$ is the coefficient related to the curing time $\tau ; \eta$ is the residuals.

The reason for selecting the above equation is that the logarithmic form properly describes the compressive strength behavior of the slag cements according to some previous studies [19, 47, 48]. To compute the value of $\alpha$, the values of compressive strength are plotted in terms of inverse curing time as shown in Figure 4. It is observed from Figure 4 that the $\psi$ values versus inverse curing time at all Blaine finenesses follow a logarithmic form. The correlation coefficients for all fitted equations are about 0.98 . The curve related to each Blaine fineness has its own value of $\alpha$.

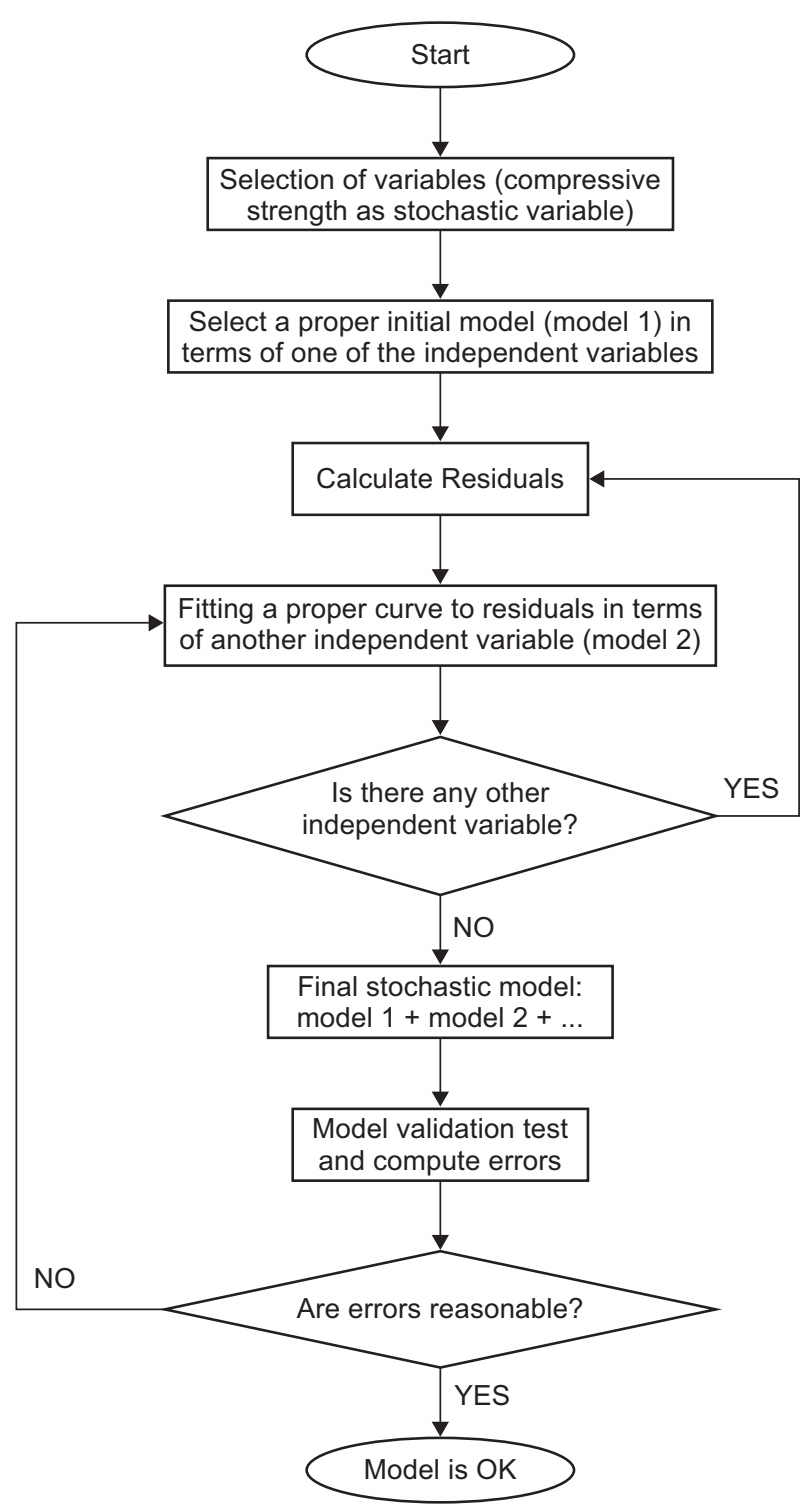

Figure 3. Steps for obtaining the primary compressive strength prediction model.

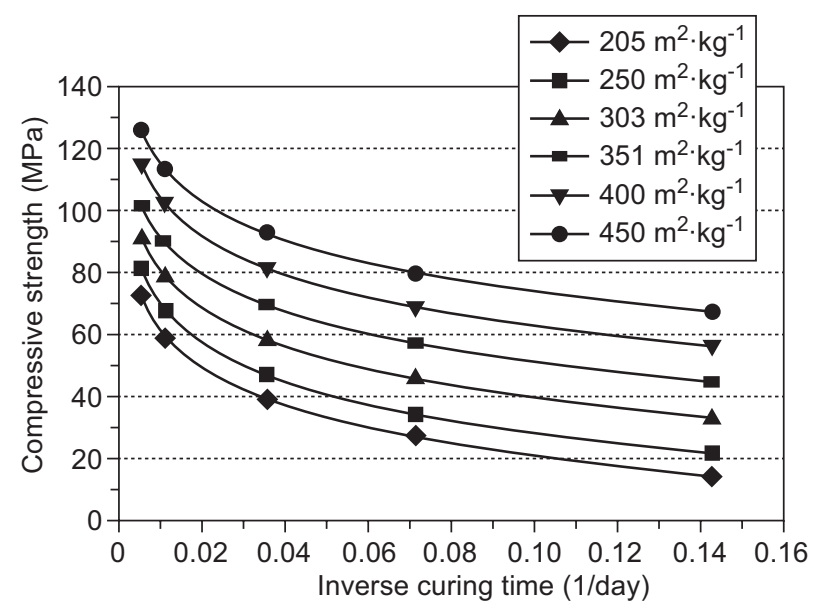

Figure 4. Variation of compressive strength of CAPHSC mortar versus inverse curing time. 
The values of $\alpha$ associated with all Blaine finenesses are given in Table 3. Inasmuch as the values of $\alpha$ are close together, their average is calculated and considered as the coefficient of curing time in Equation 1.

Again, Equation 1 is re-written in the form of Equation 2 that it is as follows:

$$
\psi=-17.873 \cdot \ln (1 / \tau)+\eta
$$

Table 3. Values of $\alpha$ for all Blaine finenesses used in our experimental work.

\begin{tabular}{cc}
\hline Blaine fineness $\left(\mathrm{m}^{2} \cdot \mathrm{kg}^{-1}\right)$ & $\alpha$ \\
\hline 205 & -17.66 \\
250 & -18.14 \\
303 & -17.97 \\
351 & -17.95 \\
400 & -17.97 \\
450 & -17.55 \\
\hline
\end{tabular}

Next step of the primary modeling is to compute the values of residuals and plot them against Blaine finness. The residuals are calculated from Equation 3

$$
\eta=\psi_{\text {experimental }}-\psi_{\text {Equation } 2}
$$

In accordance with Equation 3, if the $\psi$ calculated from Equation 2 is subtracted from the experimental $\psi$, the values of residuals are obtained. The plot of the residuals versus the Blaine fineness has been illustrated in Figure 5.

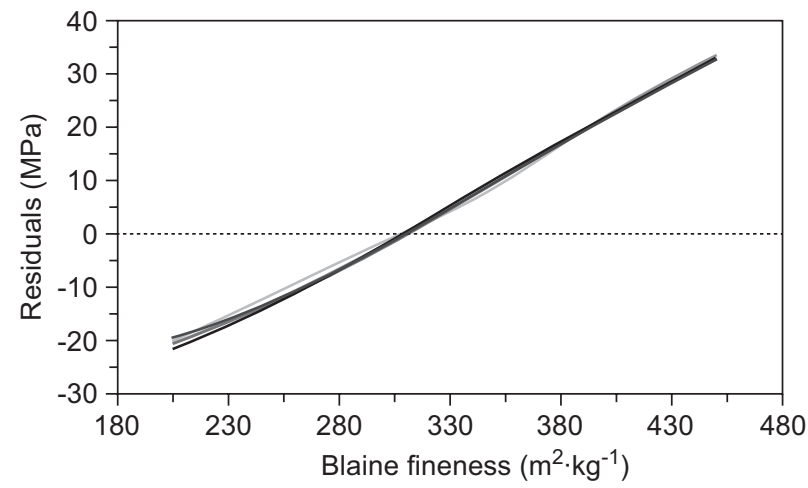

Figure 5. Variation of compressive strength residuals versus Blaine fineness.

As it is seen from Figure 5, the compressive strength residuals in terms of the Blaine fineness follow a linearity form. By fitting linear relationship to the residuals, Equation 4 is obtained

$$
\eta=0.2198 \gamma-66.702
$$

The correlation factors for all curves are about 0.99 . Finally, the AF model for prediction of compressive strength of CAPHSC mortar is summation of Equations 2 and 4 and it is described in Equation 5

$$
\psi=-17.873 \cdot \ln (1 / \tau)+0.2198 \gamma-66.702
$$

Phase 2: incorporation of composition

In phase 1 , we obtained a primary model called AF model using our experimental results. This model is in terms of curing time and Blaine fineness. In phase 2, the composition variables including weight fractions of PHS, PC, and the activator based on a dataset presented in Table 4 are taken into account.

Table 4. Compressive strength data for PHS containing cement taken from the literature [49].

\begin{tabular}{ccccc}
\hline $\begin{array}{c}\text { Blaine fineness } \\
\left(\mathrm{m}^{2} \cdot \mathrm{kg}^{-1}\right)\end{array}$ & $\begin{array}{c}\text { PHS content } \\
(\text { wt. \%) }\end{array}$ & \multicolumn{3}{c}{ Compressive strength $(\mathrm{MPa})$} \\
\cline { 3 - 5 } 3 days & 28 days & 56 days \\
\hline \multirow{3}{*}{393} & 10 & 22.6 & 48.8 & 57.8 \\
& 30 & 15.9 & 35.8 & 48.3 \\
& 50 & 9.0 & 20.9 & 30.8 \\
\hline \multirow{3}{*}{401} & 10 & 20.4 & 45.8 & 50.8 \\
& 30 & 15.5 & 35.4 & 42.6 \\
& 50 & 8.8 & 22.7 & 35.1 \\
\hline \multirow{3}{*}{422} & 10 & 22.4 & 49.1 & 55.8 \\
& 30 & 12.2 & 33.1 & 40.5 \\
& 50 & 10.5 & 23.9 & 31.7 \\
\hline
\end{tabular}

In fact, modification of the AF model is performed by using a coefficient that involves mentioned weight fractions in the AF model. Therefore, Equation 5 is modified as shown in Equation 6:

$$
\psi^{*}=(-17.873 \cdot \ln (1 / \tau)+0.2198 \gamma-66.702) \cdot \beta
$$

where $\psi^{*}$ is the initially predicted compressive strength.

The main focus in this phase is to find $\beta$ as a stochastic function. Figure 6 illustrates a schematic presentation of the modeling process in this phase.

At first, curing time and Blaine fineness data from Table $4\left(\tau_{i}\right.$ and $\left.\gamma_{i}\right)$ are applied to the AF model and the primary compressive strength data $\left(\psi_{i}\right)$ are obtained. In next step in this phase, $\beta_{j}$ coefficients are calculated by dividing experimental compressive strength data in Table 4 to values of $\psi_{i}$ according to Equation 7 :

$$
\beta_{j}=\frac{C S_{\text {experimental }}}{C S_{A F-\text { model }}}
$$

in which $C S$ is the compressive strength.

The values of $\beta_{j}$ are presented in Table 5. Average of $\beta_{j}$ coefficients for each Blaine fineness is computed $(\bar{\beta})$ and then a stochastic linear equation is considered for fitting each $\bar{\beta}_{j}$ coefficient. This linear equation is as a function of weight fractions of PHS and PC as presented in Equation 8:

$$
\bar{\beta}_{j}=a_{j} P+b_{j} C
$$

where $P$ is weight fraction of PHS; and $C$ is weight fraction of $\mathrm{PC}$. 


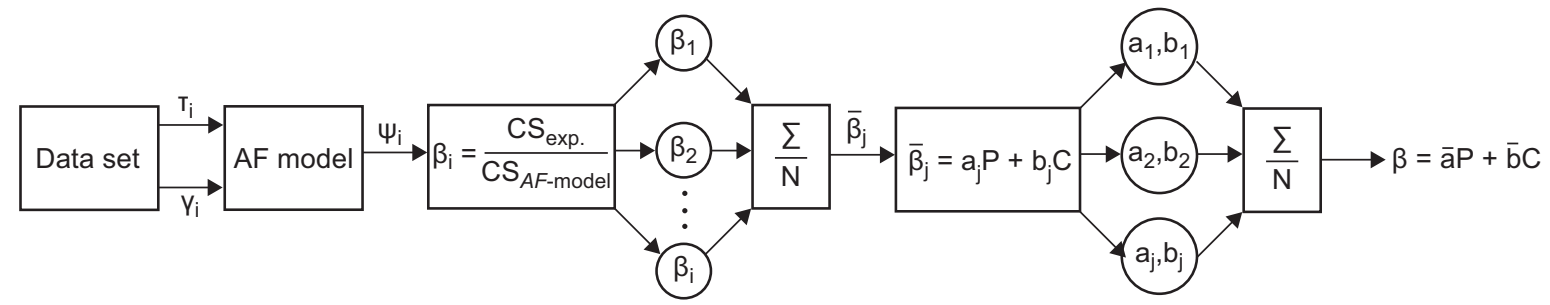

Figure 6. Schematic presentation of the modeling process in phase 2.

Table 5. Values of $\beta_{i}$ coefficients calculated from Equation 7.

\begin{tabular}{ccccc}
\hline $\begin{array}{c}\text { Blaine fineness } \\
\left(\mathrm{m}^{2} \cdot \mathrm{kg}^{-1}\right)\end{array}$ & $\begin{array}{c}\text { PHS content } \\
(\text { wt. \% })\end{array}$ & 3 days & 28 days & 56 days \\
\hline \multirow{3}{*}{393} & 10 & 0.575 & 0.616 & 0.631 \\
& 30 & 0.404 & 0.452 & 0.527 \\
& 50 & 0.229 & 0.264 & 0.336 \\
\hline \multirow{2}{*}{401} & 10 & 0.519 & 0.578 & 0.555 \\
& 30 & 0.394 & 0.447 & 0.465 \\
& 50 & 0.224 & 0.286 & 0.383 \\
\hline \multirow{2}{*}{422} & 10 & 0.570 & 0.619 & 0.609 \\
& 30 & 0.310 & 0.418 & 0.442 \\
& 50 & 0.267 & 0.302 & 0.346 \\
\hline
\end{tabular}

In this way, coefficients of $a_{j}$ and $b_{j}$ associated with each Blaine fineness are determined. Final $\beta$ coefficient as given in Equation 9 is made by replacing $a_{j}$ and $b_{j}$ with the average of $a_{j}(\bar{a})$ and the average of the $b_{j}(\bar{b})$ coefficients:

$$
\beta=-0.113 P+0.638 C
$$

To determine the numerical coefficeint of the activator, this point was considered that $\beta$ coefficient is equal to unity for CAPHSC mortars and the weight fraction of the activator used in the composition of CAPHSC as mentioned earlier is 0.06 , thus:

$$
\beta=-0.113 P+0.638 C+16.685 A
$$

Because the AF model, namely $\psi$, was derived from our original experimental data and the $\beta$ function was obtained from data taken from a different reference, modification of the $\psi^{*}$ as what is shown in Equation 11 is required. This modification method has been suggested based on programming in MATLAB software environment.

$$
\psi^{* *}=\psi^{*} \pm\left|\frac{\psi+\psi^{*}}{\psi-\psi^{*}}\right|
$$

Where the sign + or - is determined using $Q$ factor in Equation 12 so that if $Q$ factor is less than or equal to 5, the sign is - and if $Q$ factor is larger than 5, the sign + is applied. Also, if $Q$ factor is larger than 25, we use $2\left|\left(\psi+\psi^{*}\right) /\left(\psi-\psi^{*}\right)\right|$ instead of $\left|\left(\psi+\psi^{*}\right) /\left(\psi-\psi^{*}\right)\right|$ in Equation 11.

$$
Q=\left(\frac{P}{0.8}\right)\left|2 \psi^{*}-\psi\right|
$$

Finally, the model for prediction of the compressive strength of PHSC mortars is given in Equation 13:

$$
\begin{aligned}
& \psi^{*}=(-17.873 \operatorname{Ln}(1 / \tau)+0.2198 \gamma-66.702) \times \beta \\
& \beta=-0.113 P+0.638 C+16.685 A \\
& \psi^{* *}=\psi^{*} \pm\left|\frac{\psi+\psi^{*}}{\psi-\psi^{*}}\right|
\end{aligned}
$$

\section{Model validation}

To assess the validation of the proposed model, two approaches were considered. The first approach is to reproduce datasets used in the modeling and the second one is to predict the compressive strength values that have not been used in the modeling and to compare them

\begin{tabular}{|c|c|c|c|c|}
\hline \multirow{2}{*}{$\begin{array}{l}\text { Blaine fineness } \\
\qquad\left(\mathrm{m}^{2} \cdot \mathrm{kg}^{-1}\right)\end{array}$} & \multirow{2}{*}{$\begin{array}{l}\text { PHS content } \\
\text { (wt. \%) }\end{array}$} & \multicolumn{3}{|c|}{ Compressive strength $(\mathrm{MPa})$} \\
\hline & & 3 days & 28 days & 56 days \\
\hline \multirow{3}{*}{393} & 10 & $\begin{array}{c}20.5 \\
(22.6)\end{array}$ & $\begin{array}{c}45.0 \\
(48.8)\end{array}$ & $\begin{array}{c}55.2 \\
(57.8)\end{array}$ \\
\hline & 30 & $\begin{array}{c}13.8 \\
(15.9)\end{array}$ & $\begin{array}{c}35.1 \\
(35.8)\end{array}$ & $\begin{array}{c}45.2 \\
(48.3)\end{array}$ \\
\hline & 50 & $\begin{array}{l}11.0 \\
(9.0)\end{array}$ & $\begin{array}{c}22.5 \\
(20.9)\end{array}$ & $\begin{array}{c}27.4 \\
(30.8)\end{array}$ \\
\hline \multirow{3}{*}{401} & 10 & $\begin{array}{c}19.3 \\
(20.4)\end{array}$ & $\begin{array}{c}41.9 \\
(45.8)\end{array}$ & $\begin{array}{c}48.9 \\
(50.8)\end{array}$ \\
\hline & 30 & $\begin{array}{c}14.4 \\
(15.5)\end{array}$ & $\begin{array}{c}32.0 \\
(35.4)\end{array}$ & $\begin{array}{c}41.0 \\
(42.6)\end{array}$ \\
\hline & 50 & $\begin{array}{l}10.5 \\
(8.8) \\
\end{array}$ & $\begin{array}{c}23.0 \\
(22.7) \\
\end{array}$ & $\begin{array}{c}32.9 \\
(35.1) \\
\end{array}$ \\
\hline \multirow{3}{*}{422} & 10 & $\begin{array}{c}20.9 \\
(22.4)\end{array}$ & $\begin{array}{c}45.1 \\
(49.1)\end{array}$ & $\begin{array}{c}52.1 \\
(55.8)\end{array}$ \\
\hline & 30 & $\begin{array}{c}14.5 \\
(12.2)\end{array}$ & $\begin{array}{c}32.8 \\
(33.1)\end{array}$ & $\begin{array}{c}38.9 \\
(40.5)\end{array}$ \\
\hline & 50 & $\begin{array}{c}13.8 \\
(10.5)\end{array}$ & $\begin{array}{c}20.6 \\
(23.9)\end{array}$ & $\begin{array}{c}29.2 \\
(31.7)\end{array}$ \\
\hline
\end{tabular}
with the corresponding experimental values. Figures $7 \mathrm{a}$ and $7 \mathrm{~b}$ depict the original system surface related to our experimental data to be modeled and the system generated by the proposed model, respectively.

Table 6. Reproduction of the compressive strength data taken from a different source [49].

Note: Data in parentheses are experimental results. 


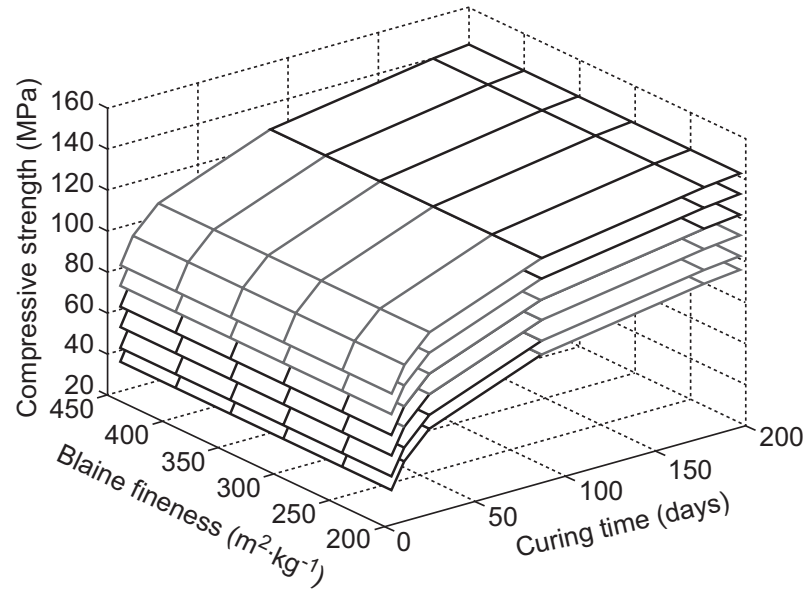

a)

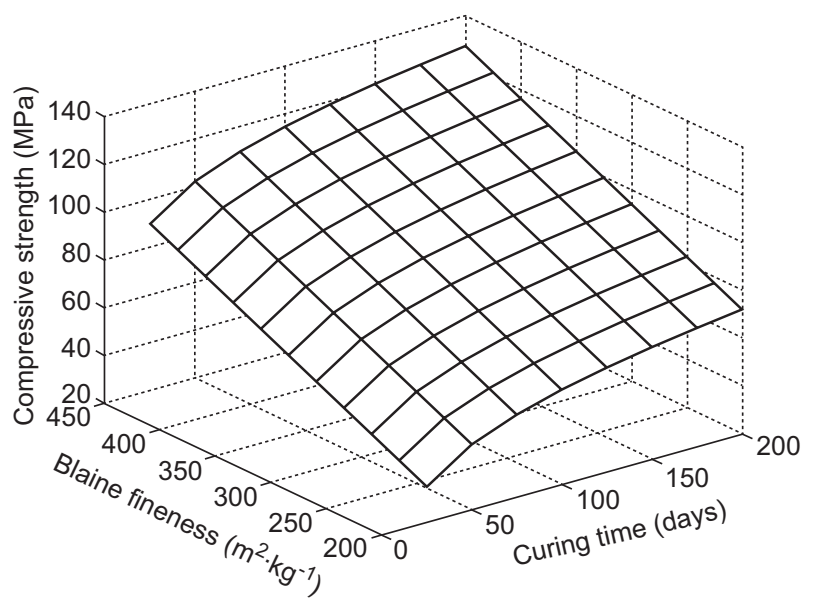

b)

Figure 7. Original system to be modeled (a) and system generated by proposed model (b).

It is found out from Figure 7a that the original system depicts a general nonlinear behavior at a constant Blaine fineness and a general linear behavior in a constant curing time. And this is what the model properly estimates as shown in Figure $7 b$.

A comparison has been presented in Figure 8 between the measured 7-, 14-, 28-, 90-, and 180-day compressive strengths and predicted ones by the model.

As it is obvious in Figure 8, the values obtained from the proposed model are very close to the experimental results. Table 6 lists the reproduction of experimental data adopted from a different reference. The data reveal that the proposed model is suitable, with predicted compressive strength values being similar to experimentally obtained values. The comparison between the experimental and predicted 270-day compressive strength of CAPHSC mortar at Blaine finenesses of 303, 351, 400, and $450 \mathrm{~m}^{2} \mathrm{~kg}^{-1}$ has been shown in Figure 9. As it is clear from this figure, the experimental and predicted 270-day compressive strength are close together.

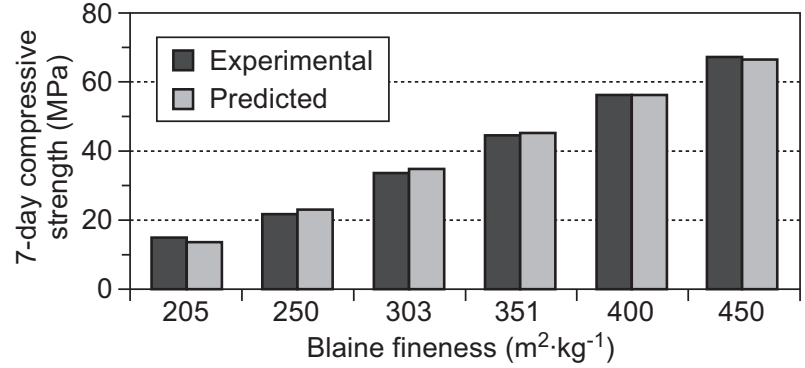

a)

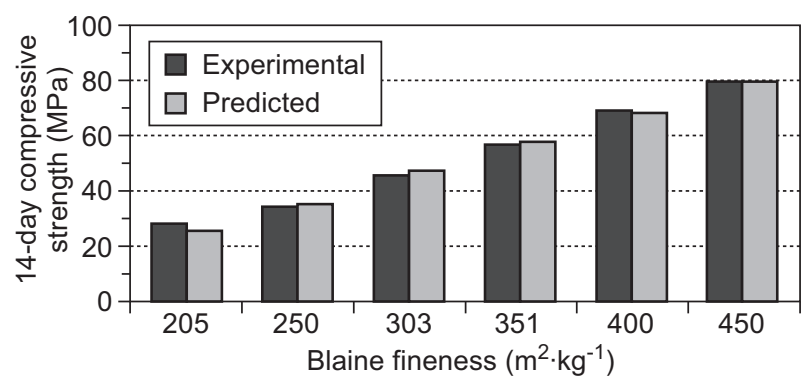

b)

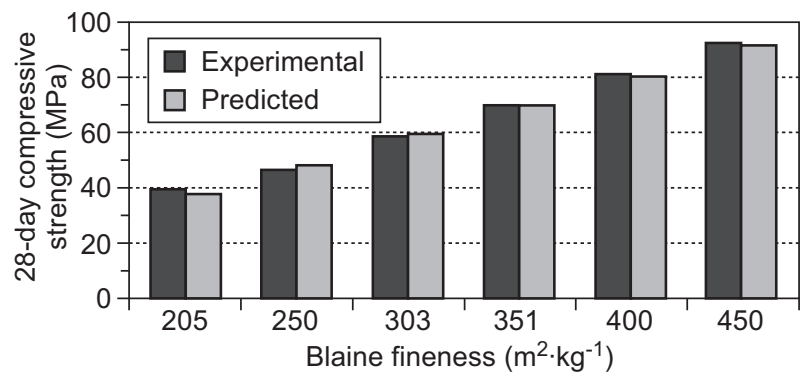

c)

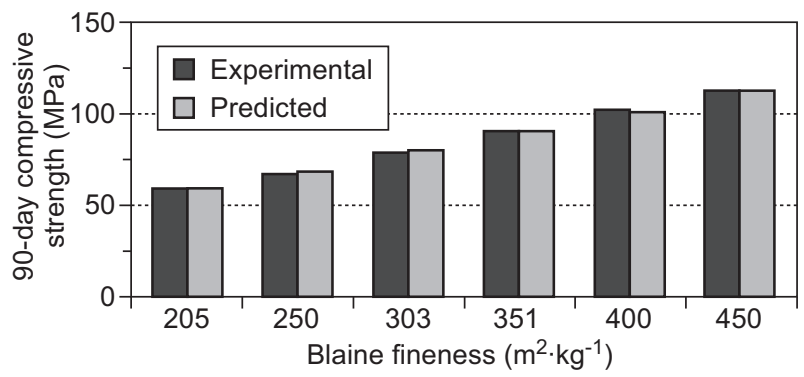

d)

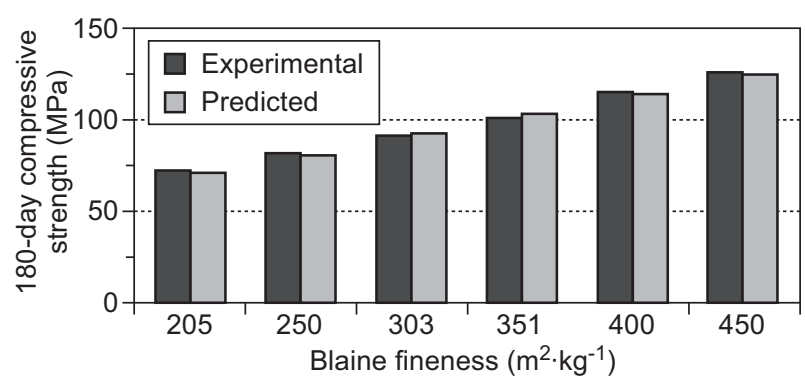

e)

Figure 8. Comparison of experimental and predicted compressive strengths of CAPHSC at various Blaine finenesses and curing times. 


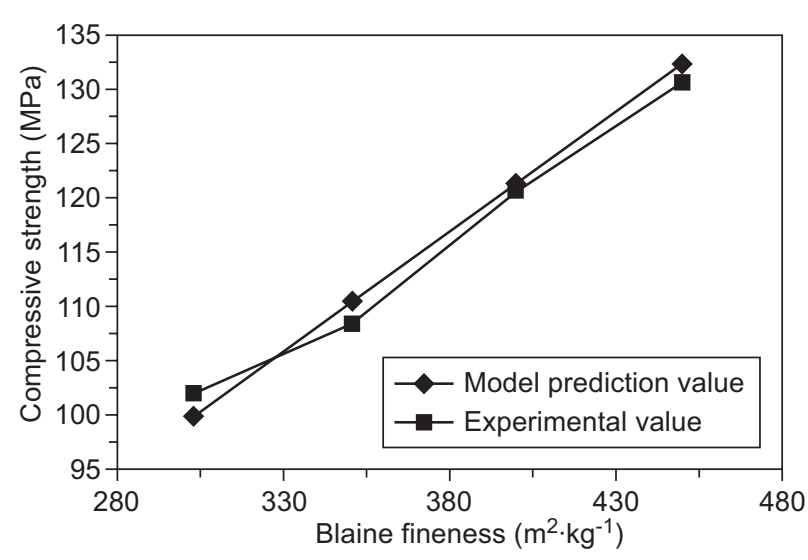

Figure 9. Comparison of the experimental and predicted 270day compressive strength of CAPHSC.

The model predicted 270-day compressive strength of CAPHSC mortar at Blaine finenesses of 303, 351, 400 , and $450 \mathrm{~m}^{2} \cdot \mathrm{kg}^{-1}$ with an error of $2.00,1.88,0.46$, and $1.22 \%$, respectively. Also, some raw data were applied from a different source to the proposed model to create some predictions and compared them with the experimental values. Table 7 presents the raw data that have not been used in the modeling process and their corresponding estimated values. The results in Table 7 confirm the reliability of the proposed model for the estimation of the PHSC compressive strength with curing time, Blaine fineness, and weight fractions of PHS, PC, and the activator.

Table 7. Prediction of the PHSC compressive strengths taken from a different source [49].

\begin{tabular}{|c|c|c|c|c|}
\hline \multirow{2}{*}{$\begin{array}{l}\text { Blaine fineness } \\
\qquad\left(\mathrm{m}^{2} \cdot \mathrm{kg}^{-1}\right)\end{array}$} & \multirow{2}{*}{$\begin{array}{l}\text { PHS content } \\
\text { (wt. \%) }\end{array}$} & \multicolumn{3}{|c|}{ Compressive strength $(\mathrm{MPa})$} \\
\hline & & 3 days & 28 days & 56 days \\
\hline \multirow{3}{*}{463} & 10 & $\begin{array}{l}22.5 \\
(21.3)\end{array}$ & $\begin{array}{c}48.2 \\
(44.2)\end{array}$ & $\begin{array}{c}55.4 \\
(53.0)\end{array}$ \\
\hline & 30 & $\begin{array}{c}18.9 \\
(17.9)\end{array}$ & $\begin{array}{c}36.1 \\
(35.2)\end{array}$ & $\begin{array}{c}36.3 \\
(32.8)\end{array}$ \\
\hline & 50 & $\begin{array}{c}14.7 \\
(12.7)\end{array}$ & $\begin{array}{c}26.7 \\
(28.2)\end{array}$ & $\begin{array}{c}29.9 \\
(32.3)\end{array}$ \\
\hline \multirow{3}{*}{494} & 10 & $\begin{array}{c}18.8 \\
(20.8)\end{array}$ & $\begin{array}{c}50.9 \\
(45.6)\end{array}$ & $\begin{array}{c}58.4 \\
(54.5)\end{array}$ \\
\hline & 30 & $\begin{array}{c}18.7 \\
(16.2)\end{array}$ & $\begin{array}{c}38.6 \\
(39.6)\end{array}$ & $\begin{array}{c}47.9 \\
(50.6)\end{array}$ \\
\hline & 50 & $\begin{array}{l}11.7 \\
(9.4) \\
\end{array}$ & $\begin{array}{c}28.6 \\
(27.7)\end{array}$ & $\begin{array}{c}40.7 \\
(42.9) \\
\end{array}$ \\
\hline \multirow{3}{*}{516} & 10 & $\begin{array}{l}18.6 \\
(21.4)\end{array}$ & $\begin{array}{c}42.7 \\
(43.5)\end{array}$ & $\begin{array}{c}58.4 \\
(55.5)\end{array}$ \\
\hline & 30 & $\begin{array}{c}19.5 \\
(17.0)\end{array}$ & $\begin{array}{c}40.4 \\
(40.1)\end{array}$ & $\begin{array}{c}46.7 \\
(51.0)\end{array}$ \\
\hline & 50 & $\begin{array}{l}12.44 \\
(10.6)\end{array}$ & $\begin{array}{c}24.9 \\
(22.8)\end{array}$ & $\begin{array}{l}33.13 \\
(36.8)\end{array}$ \\
\hline
\end{tabular}

Note: Data in parentheses are experimental results.
The performed comparisons in Figures 7-9 and also the results presented in Tables 6 and 7 show that the suggested stochastic model is capable of predicting the compressive strength of PHSC mortars with reasonably good agreement. Using this model, it is possible to predict the compressive strength of PHSC mortars at various curing times, Blaine finenesses, and compositions including three variables of PHS content, PC content, and the activator content. Inasmuch as two various datasets from two different sources were used for the modeling, so it should be noted that the error of the proposed model can be originated from different sources such as the precision of the measuring instruments, the precision of the observers, the precision of the calculations, and the peripheral effects. Extrapolation of data beyond the days used in this study can result in some errors in the values predicted by the model. This is, however, inevitable in mathematical calculations.

\section{CONCLUSIONS}

In this study, two phases were executed for stochastic modeling of compressive strength of chemically activated phosphorous slag content cement. In phase 1 , based on a certain construction route, a stochastic primary model which takes into account the effect of Blaine fineness and curing time was developed to predict the compressive strength of the cement. In phase 2, the primary model was modified using a function including weight fractions of phosphorus slag, Portland cement, and the activator. The proposed model is based on experimental results taken from various sources and includes three parts. The first part is a logarithmic equation in terms of curing time; the second part is in a linearity form in terms of Blaine fineness, and the third part is related to a coefficient that is a linear function including mix composition. The suggested compressive strength model was verified for efficient prediction of compressive strength of phosphorus slag containing cement mortars. All of the results obtained from the model show relatively excellent agreement with experimental results.

\section{REFERENCES}

1. Dongxu L., Xuenquan W., Jinlin S., Yujiang W. (2000): The influence of compound admixtures on the properties of high-content slag cement. Cement and Concrete Research, 30, 45-50. doi:10.1016/S0008-8846(99)00210-0

2. Kumar S., Kumar R., Bandopadhyay A. (2006): Innovative methodologies for the utilization of wastes from metallurgical and allied industries. Resources, Conservation and Recycling, 48, 301-314. doi:10.1016/j. resconrec.2006.03.003

3. Hekal E.E., Abo-El-Enein S.A., El-Korashy S.A., Megahed G.M., El-Sayed T.M. (2013): Hydration characteristics of Portland cement-Electric arc furnace slag blends. HBRC Journal, 9, 118-124. doi:10.1016/j.hbrcj.2013.05.006 
4. Palaniappan K.A., Vasantha S., Prakasan S.S., Prabhu S. (2013): GGBS as alternative to OPC in concrete as an environment pollution reduction approach. International Journal of Engineering Research and Technology, 2(6), 190-195.

5. Kumar S., Kumar R., Bandopadhyay A., Alex T.C., Ravi Kumar B., Das S.K., Mehrotra S.P. (2008): Mechanical activation of granulated blast furnace slag and its effect on the properties and structure of portland slag cement. Cement and Concrete Composites, 30, 679-685. doi:10.1016/j. cemconcomp.2008.05.005

6. Zhu J., Zhong Q., Chen G., Li D. (2012): Effect of particlesize of blast furnace slag on properties of portland cement. Procedia Engineering, 27, 231-236. doi:10.1016/j. proeng.2011.12.448

7. Sudarsono A., Kosasih K.M. (2000): Study on the making of blended cement by mixing granulated blast furnace slag with Portland cement clinker. PROC ITB, 32, 47-51.

8. Abdelkader B., El-Hadj K., Karim E. (2010): Efficiency of granulated blast furnace slag replacement of cement according to the equivalent binder concept. Cement and Concrete Composites, 32, 226-231. doi:10.1016/j. cemconcomp.2009.11.004

9. Tsakiridis P.E., Papadimitriou G.D., Tsivilis S., Koroneos C. (2008): Utilization of steel slag for Portland cement clinker production. Journal of Hazardous Materials, 152, 805-811. doi:10.1016/j.jhazmat.2007.07.093

10. Huang Y., Lin Z.S. (2010): Investigation on phosphogypsum-steel slag-granulated blast-furnace slag-limestone cement. ConstructionandBuilding Materials, 24, 1296-1301. doi:10.1016/j.conbuildmat.2009.12.006

11. Marriaga J.L., Claisse P., Ganjian E. (2011): Effect of Steel Slag and Portland Cement in the Rate of Hydration and Strength of Blast Furnace Slag Pastes. Journal of Materials in Civil Engineering, 23(2), 153-160. doi: 10.1061/(ASCE) MT.1943-5533.0000149

12. Dong X.L., Lin C., Zhong-zi X., Zhi-min L. (2002): A blended cement containing blast furnace slag and phosphorous slag. Journal of Wuhan University of Technology, 17(2), 62-65. doi:10.1007/BF02832625

13. Peiwei G., Xiaolin L., Chuanxi Y., Xiaoyan L., Nannan S., Shaochun J. (2008): Microstructure and pore structure of concrete mixed with superfine phosphorous slag and superplasticizer. Construction and Building Materials, 22, 837-840. doi:10.1016/j.conbuildmat.2006.12.015

14. Xia C., Li Z., Kunhe F. (2009): Anti-Crack Performance of Phosphorus Slag Concrete. Wuhan University Journal of Natural Sciences, 14(1), 80-86. doi: 10.1007/s11859-0090117-9

15. Xia C., Kunhe F., Huaquan Y., Hua P. (2011): Hydration kinetics of phosphorous slag-cement paste. Journal of Wuhan University of Technology-Mater. Sci. Ed., 26(1), 142-146. doi:10.1007/s11595-011-0186-4

16. Bellmann F., Stark J. (2009): Activation of blast furnace slag by a new method. Cement and Concrete Research, 39, 644-650. doi:10.1016/j.cemconres.2009.05.012

17. Ben Haha M., Lothenbach B., Le Saout G., Winnefeld F. (2012): Influence of slag chemistry on the hydration of alkali-activated blast-furnace slag-Part II: Effect of $\mathrm{Al}_{2} \mathrm{O}_{3}$. Cement and Concrete Research, 42, 74-83. doi:10.1016/j. cemconres.2011.08.005

18. Chen L. (2010): A multiple linear regression prediction of concrete compressive strength based on physical properties of electric arc furnace oxidizing slag. International Journal of Applied Science and Engineering, 7(2), 153-158.

19. Allahverdi A., Mahinroosta M. (2013): Mechanical activation of chemically activated high phosphorous slag content cement. Powder Technology, 245, 182-188. doi:10.1016/j.powtec.2013.04.037

20. Allahverdi A., BahriRashtAbadi M.M. (2014): Resistance of chemically activated high phosphorous slag content cement against frost-salt attack. Cold Regions Science and Technology, 98, 18-25. doi:10.1016/j.coldregions. 2013.11.001

21. Allahverdi A., Ghorbani J. (2006): Chemical activation and set acceleration of lime-natural pozzolan cement. Ceramics Silikaty, 50, 193-199.

22. Allahverdi A., Rahmani A. (2009): Chemical activation of natural pozzolan with a solid compound activator. Cement Wapno Beton, 4, 205-213.

23. Allahverdi A., Saffari M. (2011). Chemical activation of phosphorous slag with a solid compound activator, in: Proceedings of $4^{\text {th }}$ International Conference on non-traditional cements and concretes. Brno, Czech Republic, 573-580.

24. Sam M.K. (2003). Predicting the compressive strength of concrete, in: Proceedings of $28^{\text {th }}$ conference on our world in concrete \& structures. Singapore, 467-474.

25. Hasn M.M., Kabir A. (2011). Prediction of compressive strength of concrete from early age test result, in: Proceedings of $4^{\text {th }}$ annual paper meet and $1^{\text {st }}$ civil engineering congress. Dhaka, Bangladesh, 1-7.

26. Iqbal Khan M. (2009): Analytical model for the strength prediction of HPC consisting of cementitious composites. Architecture Civil Engineering Environment, 1, 89-96.

27. Eswari S., Raghunath P.N., Kothandaraman S. (2011): Regression modeling for strength and toughness evaluation of hybrid fibre reinforced concrete. ARPN Journal of Engineering and Applied Sciences, 6(5), 1-8.

28. Akkurt S., Ozdemir S., Tayfur G., Akyol B. (2003): The use of GA-ANNs in the modeling of compressive strength of cement mortar. Cement and Concrete Research, 33, 973 979. doi:10.1016/S0008-8846(03)00006-1

29. Baykasoglu A., Dereli T., Tanis S. (2004): Prediction of cement strength using soft computing techniques. Cement and Concrete Research, 34, 2083-2090. doi:10.1016/j. cemconres.2004.03.028

30. Öztas A., Pala M., EÖzbay E., Kanca E., Cag Iar N., Asghar M. (2006): Prediction the compressive strength and slump of high strength concrete using neural network. Construction and Building Materials, 20, 769-775. doi:10.1016/j.conbuildmat.2005.01.054

31. Bilim C., Atis C.D., Tanyildizi H., Karahan O. (2009): Predicting the compressive strength of ground granulated blast furnace slag. Advances in Engineering Software, 40, 334-340. doi:10.1016/j.advengsoft.2008.05.005

32. Saridemir M. (2009): Prediction of compressive strength of concretes containing metakaolin and silica fume by artificial neural networks. Advances in Engineering Software, 40, 350-355. doi:10.1016/j.advengsoft.2008.05.002

33. Subasi. A., Yilmaz A.S., Binici H. (2009): Prediction of early heat of hydration of plain and blended cements using neuro-fuzzy modeling techniques. Expert System with Applications, 36, 4940-4950. doi:10.1016/j.eswa.2008.06. 015 
34. Onal O., Oztutk A.U. (2010): Artificial neural network application on microstructure-compressive strength relationship of cement mortar. Advances in Engineering Software, 41, 165-169. doi:10.1016/j.advengsoft.2009.09.004

35. Saridemir M. (2010): Genetic programming approach for prediction of compressive strength of concretes containing rice husk ash. Construction and Building Materials, 24, 1911-1919. doi:10.1016/j.conbuildmat.2010.04.011

36. Atici U. (2011): Prediction of the strength of mineral admixture concrete using multivariable regression analysis and an artificial neural network. Expert Systems with Applications, 38, 9609-9618. doi:10.1016/j.eswa.2011.01. 156

37. Nath U.K., Goyal M.K., Nath T.P. (2011): Prediction of compressive strength of concrete using neural network. International Journal of emerging trends in Engineering and Development, 1, 32-43.

38. Christensen P.T. (2002): Stochastic modeling of the diffusion coefficient for concrete, in: Proceedings of IFIP Working Conference, Osaka, Japan.

39. Menadi B., Kenai S., Khatib J.M., Ait-Mokhtar A. (2009). Strength development and prediction of mortars containing limestone fines, in: SBEIDCO- ${ }^{\text {st }}$ International Conference on Sustainable Built Environment Infrastructures in Developing Countries. ENSET Oran, Algeria, pp. 91-98.

40. Silvestri S., Gasparini G., Trombetti T., Ceccoli C. (2008). Statistical analysis towards the identification of accurate probablity distribution models for the compressive strength of concrete, in: Proceedings of the $14^{\text {th }}$ World Conference on Earthquake Engineering. Beijing, China.

41. Tarighat A. (2012): Stochastic modeling and calibration of chloride content profile in concrete based on limited available data. International Journal of Civil Engineering, 10(4), 309-316.

42. Zelic J., Rusic D., Krstulovic R. (2004): A mathematical model for prediction of compressive strength in cementsilical fume blends. Cement and Concrete Research, 34, 2319-2328. doi:10.1016/j.cemconres.2004.04.015

43. Lin F., Meyer C. (2009): Hydration kinetics modeling of Portland cement considering the effects of curing temperature and applied pressure. Cement and Concrete Research, 39, 255-265. doi:10.1016/j.cemconres.2009.01.014

44. Allahverdi A., Mahinroosta M. (2014): A model for prediction of compressive strength of chemically activated high phosphorous slag content cement. International Journal of Civil Engineering: Structure Concrete, 12(4), 481-487.

45. Taylor H.M., Karlin S. (1998). An introduction to stochastic modeling. $3^{\text {rd }}$ ed. Academic Press, London, UK.

46. Scott M. (2013): Applied stochastic processes in science and engineering. University of Waterloo, CND.

47. Sajedi F., Abdul Razak H. (2011): Comparison of different methods for activation of ordinary Portland cement-slag mortars. Construction and Building Materials, 25(1), 3038. doi:10.1016/j.conbuildmat.2010.06.060

48. Sajedi F. (2012): Using heat treatment method for activation of OPC-slag mortars. INTECH, chapter 16, 385-408.

49. Xun X., Yao Z., Sanxia L. (2012): Influence of different localities phosphorous slag powder on the performance of Portland cement. Procedia Engineering, 27, 1339-1346. doi:10.1016/j.proeng.2011.12.591 